\title{
A Human Rights-Based Approach in Implementing Sustainable Development Goal 4 (Quality Education) for Ethnic Minorities in Vietnam
}

\author{
Doanh-Ngan-Mac Do ${ }^{1}$, Linh-Khanh Hoang ${ }^{2}$, Cuong-Minh Le ${ }^{3, *(\mathbb{D})}$ and Trung Tran ${ }^{4, *(\mathbb{D})}$ \\ 1 Faculty of Law and Social Management, Thai Nguyen University of Sciences, Thai Nguyen 250000, Vietnam; \\ domacngandoanh@tnus.edu.vn \\ 2 Institute of Theoretical and Applied Research, Duy Tan University, Hanoi 100000, Vietnam; \\ hoangkhanhlinh2@duytan.edu.vn \\ 3 Center of Occupational Skills Development, Dong Thap University, Dong Thap 870000, Vietnam \\ 4 Department of Basic, Vietnam Academy for Ethnic Minorities, Hanoi 100000, Vietnam \\ * Correspondence: lmcuong@dthu.edu.vn (C.-M.L.); trantrung@cema.gov.vn (T.T.)
}

Received: 22 March 2020; Accepted: 18 May 2020; Published: 20 May 2020

\begin{abstract}
Seventeen sustainable development goals (SDG) by the United Nations in its 2030 Agenda have been nationalized and implemented in Vietnam. One of the country's priorities is making educational provision accessible to all of its residents, especially for marginalized groups, while enforcing their human rights. In this context, this article examines the implementation of SDG4 (quality education) in combination with the practice of human rights for ethnic minorities in Vietnam. With access to jurisprudence, this research provides a detailed assessment of the compatibility between SDG targets and the legal rights to education of ethnic minorities. Additionally, this research employs an exploratory method to investigate the four major conditions for the implementation of quality education for ethnic minorities, namely legal-political, economic, socio-cultural factors, and participation pride. We also investigate three main barriers that hinder SDG4 implementation and human rights practices, namely child labor, language, and gender inequality. The contribution of this study is necessary for establishing more informed strategies and policies towards sustainable development in education for multi-ethnic countries.
\end{abstract}

Keywords: educational rights; ethnic minorities; quality education; sustainable development goals; multi-cultural education

\section{Introduction}

Vietnam is a multi-ethnic nation with 54 ethnic groups, of which the Kinh is considered the majority [1]. The remaining 53 ethnic communities, comprising about $14.6 \%$ of the national population (13.39 million people), are considered ethnic minorities. Ethnic minorities in Vietnam often reside in harsh weather and geographical conditions and have difficult socio-economic conditions, which affects, to a certain extent, the opportunities and the implementation of human rights for them. To improve human rights practices in the country, Vietnam's Central Party Committee issued Directive No. 12-CT/TW dated 12 July 1992 to highlight the national recognition of basic human rights for Vietnamese ethnic minority groups.

Vietnam has taken the 17 sustainable development goals (SDGs) established by the United Nations for global sustainable development in the 2030 Agenda as a benchmark for the long-term development of the country. These global SDGs have been adapted into 115 Vietnam SDGs (VSDGs) to suit the nation's conditions and contexts and are included in Vietnam's National Action Plan for the implementation of the 2020 Agenda [2]. The areas of priority in Vietnam for sustainable development 
are education, vulnerable groups, and social equality, to ensure that no one is left behind. Some of the remarkable achievements so far can be seen in the reduction in inequality and the improvements made in supporting access to justice [2]. These initial successes in developing education and social justice make the country confident in the continuing prioritization of SDG4 (quality education) as a firm basis for economic, social, and cultural development [2]. In particular, as a multi-ethnic country, Vietnam is determined to develop the education of all ethnic groups without discrimination in its efforts to achieve the SDGs comprehensively.

Implementing quality education in SDG4 in ethnic minority areas in Vietnam under a human rights-based approach is a rather newly explored content. Therefore, this research is conducted by employing the jurisprudence method to explore the compatibility of SDG targets with elements of human rights in education for ethnic minorities. An exploratory aspect is added with a questionnaire to 300 respondents from Tan Trao University, Tuyen Quang Province, to investigate the legal-political, economic, socio-cultural and participation pride conditions in the implementation of human rights to ensure quality education among ethnic minority groups. With this method, barriers to implementation, including child labor, gender inequality, language and others, are also examined. Finally, further implications for both academic research and managerial practices are drawn to contribute to the improvement of SDG4 for Vietnamese ethnic minorities.

\section{Literature Review}

\subsection{An Overview of Goals and Targets for Global Sustainable Development}

In the context of growing globalization, the United Nations (UN) set up 17 global goals for sustainable development by 2030 in its 2030 Agenda. The goals address comprehensive conditions required for sustainable development, including education, poverty, climate change, equality, economic growth and so forth (Table 1).

Table 1. Sustainable Development Goals in 2030 Agenda [3].

\begin{tabular}{|c|c|c|}
\hline UN_SDGs & Definitions & Descriptions \\
\hline UN_SDG 1 & No poverty & Ending poverty in all its forms everywhere \\
\hline UN_SDG 2 & Zero hunger & $\begin{array}{l}\text { Ending hunger, achieve food security, and improved nutrition and promote } \\
\text { sustainable agriculture }\end{array}$ \\
\hline UN_SDG 3 & Good health and well-being & Ensuring healthy lives, and promote well-being for all at all ages \\
\hline UN_SDG4 & Quality education & $\begin{array}{c}\text { Ensuring inclusive and equitable quality education and promote lifelong } \\
\text { learning opportunities for all }\end{array}$ \\
\hline UN_SDG 5 & Gender equality & Achieving gender equality and empower all women and girls \\
\hline UN_SDG 6 & Clean water and sanitation & $\begin{array}{l}\text { Ensuring availability and sustainable management of water and sanitation } \\
\text { for all }\end{array}$ \\
\hline UN_SDG 7 & Affordable and clean energy & Ensuring access to affordable, reliable, sustainable and modern energy for all \\
\hline UN_SDG 8 & $\begin{array}{l}\text { Decent work and } \\
\text { economic growth }\end{array}$ & $\begin{array}{l}\text { Promoting sustained, inclusive and sustainable economic growth, full and } \\
\text { productive employment, and decent work for all }\end{array}$ \\
\hline UN_SDG 9 & $\begin{array}{l}\text { Industry, innovation, } \\
\text { and infrastructure }\end{array}$ & $\begin{array}{l}\text { Building resilient infrastructure, promote inclusive and sustainable } \\
\text { industrialization and foster innovation }\end{array}$ \\
\hline UN_SDG 10 & Reduced inequalities & Reduce inequality within and among countries. \\
\hline UN_SDG 11 & $\begin{array}{l}\text { Sustainable cities and } \\
\text { communities }\end{array}$ & Make cities and human settlements inclusive, safe, resilient, and sustainable. \\
\hline UN_SDG 12 & $\begin{array}{l}\text { Responsible consumption } \\
\text { and production }\end{array}$ & Ensure sustainable consumption and production patterns. \\
\hline UN_SDG 13 & Climate action & Take urgent action to combat climate change and its impacts \\
\hline UN_SDG 14 & Life below water & $\begin{array}{c}\text { Conserve and sustainably use the oceans, seas, and marine resources for } \\
\text { sustainable development. }\end{array}$ \\
\hline UN_SDG 15 & Life on land & $\begin{array}{c}\text { Protect, restore, and promote sustainable use of terrestrial ecosystems, } \\
\text { sustainably manage forests, combat desertification, and halt and reserve land } \\
\text { degradation and halt biodiversity loss. }\end{array}$ \\
\hline UN_SDG 16 & $\begin{array}{l}\text { Peace, justice, and strong } \\
\text { institutions }\end{array}$ & $\begin{array}{c}\text { Promote peaceful and inclusive societies for sustainable development; } \\
\text { provide access to justice for all and build effective, accountable, and inclusive } \\
\text { institutions at all levels. }\end{array}$ \\
\hline UN_SDG 17 & Partnership for the goals & $\begin{array}{l}\text { Strengthen the means of implementation and revitalize the global partnership } \\
\text { for sustainable development }\end{array}$ \\
\hline
\end{tabular}


As shown in Table 1, SDG4 is defined as concerning quality education by "ensuring inclusive and equitable quality education and promoting lifelong learning opportunity for all" [4]. Seven targets are entailed to specify SDG4, including:

(4.1) free, equitable and quality primary and secondary education for all;

(4.2) quality early childhood development and pre-primary education for all;

(4.3) access to quality technical, vocational and tertiary education for all;

(4.4) developing relevant skills for employment for all;

(4.5) the elimination of gender disparities in education and equal access to all levels of education training for the vulnerable, including indigenous people;

(4.6) literacy and numeracy for all;

(4.7) acquiring the necessary knowledge and skills for sustainable development and lifestyles, human rights, gender equality, promotion of peace and non-violence, global citizenship and appreciation of cultural diversity.

The focus of all SDG4 targets is quality education for all school levels, from primary to tertiary education and for all age groups from children to adults, irrespective of their ethnic background. Among those, Target 4.7 is considered the most crucial one in terms of its involvement in other SDGs. The target is also important to facilitate the measurement of the remaining targets, such as gender equality in Target 4.5 and necessary knowledge and skills in Targets 4.1, 4.2, 4.3 and 4.6. In a related note, Target 4.5 refers to indigenous people as one of the vulnerable groups that need to have gender inequality in education removed.

Multi-ethnic countries in the world, especially the Association of Southeast Asian Nations ASEAN, have followed distinctive approaches to implement their own SDGs. In Southeast Asia, the inevitable discrepancy in the level of economic development among ethnic minorities also leads to completely different concerns for their sustainable development. On top of that, SDG4 receives further in-depth analyses that are concretized in three middle-income countries, Indonesia, Malaysia and Vietnam [5]. A rights-based approach is mentioned as the building block for accomplishing equity, recognizing and eliminating barriers, and encouraging and supporting diversity [6].

\subsection{Sustainable Development Goal 4 (SDG4) for Ethnic Minorities}

To approach measures for vulnerable groups, the UN adopts "substantive equality" [7-11]. By targeting substantive equality, the UN resolves long-existing conflicts in equality law, while still focusing on human rights for underrepresented groups. In this way, concretized and appropriate measures can be established to develop the capacities of these vulnerable groups and promote opportunities for them to approach and enjoy their human rights.

Research on SDG4 for ethnic minorities can be divided into two periods. Before 2015, the focus of most research was placed on implementing Millennium Development Goals (MDGs) [12,13]. Nonetheless, this shifted to proposing to develop SDGs after the MDGs were found to be at fault. Refs. [14,15] signify fundamental points in SDG4 in the general context of ethnic communities. SDG4 targets educational purposes, underscoring the need to protect the principles of human rights for ethnic minorities who are still suffering from hardships [14].

After 2015, studies have mostly aimed at figuring out the most feasible ways to promote SDG4. Ref. [16] emphasizes the need to provide education for less advantaged children from all walks of life.

The children most likely to stay out of school are children from the poorest households; ethnic and linguistic minorities; working children; those in nomadic or sparsely populated areas; orphans and children affected by HIV and AIDS; slum dwellers; children with disabilities; and children living in complex emergencies. (p.9) 
Ref. [16] adds that technology alone is not enough for educational transformation. In contrast, Ref. [17] recommends "augmented reality binomial-mobile" devices and the use of lip integration technology as a breakthrough teaching methodology.

\subsection{Human Rights of Ethnic Minorities Reflected in SDG4}

Since SDGs were published and enforced, the compatibility of SDG4 with human rights has been of wide interest as it deals with the most inspiring and contentious concern, the human right to education. The targets of SDG4 have been framed using two methods, the Human Rights-Based Approach and People-Centered Advocacy. The former is defined as "both a normative and conceptual framework, based on international human rights standards and ensuring the protection and promotion of human rights for all" [18]. The core of the human rights-based approach is to ensure no discrimination in tackling the causes of poverty, particularly injustice and inequality. The latter is an approach to human rights that emphasizes the elimination of subjective factors when conducting studies in academia and government [18]. This approach requires the transformation in people's awareness that people are not passive beneficiaries or seekers of charity from the government. Instead, it is the government's political and moral responsibility to guarantee all human rights to all citizens. Therefore, people have a right to demand that the state ensure impartial social change and distributive justice [18].

As previously mentioned, Targets 4.5 and 4.7 contain the most relevant content for human rights and indigenous groups. A system of five global and thematic indicators for each is sketched out by [19] to gain a closer look at the relations (Table 2).

Table 2. Indicators for Targets 4.5 and 4.7.

\begin{tabular}{|c|c|}
\hline Global Indicators & Content \\
\hline 4.7.1 & $\begin{array}{l}\text { Extent to which (i) global citizenship education and (ii) education for sustainable } \\
\text { development, including gender equality and human rights, are mainstreamed at all } \\
\text { levels in: (a) national education policies, (b) curricula, (c) teacher education and } \\
\text { (d) student assessment }\end{array}$ \\
\hline 4.5 .1 & $\begin{array}{l}\text { Parity indices (female/male, rural/urban, bottom/top wealth quintile and others } \\
\text { such as disability status, indigenous peoples and conflict-affected) for all education } \\
\text { indicators on this list that can be disaggregated }\end{array}$ \\
\hline Thematic Indicators & Content \\
\hline 4.7 .2 & Percentage of schools that provide life skills-based HIV and sexuality education \\
\hline 4.7 .3 & $\begin{array}{l}\text { Extent to which the framework on the World Programme on Human Rights } \\
\text { Education is implemented nationally (as per the UNGA Resolution 59/113) }\end{array}$ \\
\hline 4.7.4 & $\begin{array}{l}\text { Percentage of students by age group (or education level) showing adequate } \\
\text { understanding of issues relating to global citizenship and sustainability }\end{array}$ \\
\hline 4.7.5 & $\begin{array}{c}\text { Percentage of 15-year-old students showing proficiency in knowledge of } \\
\text { environmental science and geoscience }\end{array}$ \\
\hline 4.5 .2 & $\begin{array}{c}\text { Percentage of students in primary education whose first or home language is the } \\
\text { language of instruction }\end{array}$ \\
\hline 4.5 .3 & $\begin{array}{c}\text { Extent to which explicit formula-based policies reallocate education resources to } \\
\text { disadvantaged populations }\end{array}$ \\
\hline 4.5.4 & Education expenditure per student by level of education and source of funding \\
\hline 4.5 .5 & Percentage of total aid to education allocated to least developed countries \\
\hline
\end{tabular}

The global indicator (GI) is drawn based on the implementation of the 1974 UNESCO Recommendation concerning Education for International Understanding, Co-operation and Peace Education relating to Human Rights and Fundamental Freedoms. It measures the extent to which countries offer Global Citizenship Education (GCED), including gender equality and human rights education, and Education for Sustainable Development (ESD) in their education systems. For this purpose, four aspects of education systems are examined, including educational policies, curricula, teacher training and student assessment [20]. GI 4.7.1 takes another responsibility for developing 
and maintaining the thematic indicators (TI) that serve as the follow-up and review tools of SDG4. GCED and ESD are considered the two indispensable factors for achieving SDG4 as they guarantee quality education and other targets involved in SDG4. Globally, an increasing number of countries are applying GI as a reflection of their human rights and fundamental freedom principles in in-service teacher education. In recognition of this growing trend, the Inter-Agency and Expert Group on SDG Indicators has recently upgraded their tier classification for GI 4.7.1 from tier III to tier II. In other words, GI 4.7.1 is "conceptually clear, has an intentionally established methodology and standards are available, but data are not regularly produced by countries". At the same time, Target 4.5 receives far wider recognition, as its GI is positioned at tier I and II [20].

In Vietnam, human rights for ethnic minorities have received much consideration in a variety of research fields, especially in education [21,22]. Ongoing practical efforts have also been made to build a national policy and legal system for underrepresented groups in accordance with international laws, especially in preserving minority languages and culture in education rights [9,10]. Moreover, the Central Party and the Government of Vietnam demonstrate the basic need to incorporate the human rights of ethnic minorities in the Constitution of Vietnam as an indispensable move in maintaining a peaceful, prosperous and happy life for all ethnic communities. Among the essential issues to tackle, education, considered in close relation with human rights, will contribute to a comprehensive analysis of the SDGs from a legal perspective [23].

\subsection{Quality Education in the Multicultural Context of Education}

\subsubsection{Quality Education}

Quality education, the focus of SDG4, is the core of Education for Sustainable Development. Ref. [24] categorize quality education in the top priority group for achieving sustainability. In agreement, Ref. [25] emphasizes the utmost importance of quality education to the holistic and sustainable development of schooling. Quality education is recognized by four main features, namely the availability of educational infrastructure, accessibility by all with no discrimination, acceptability of methods and adaptability to learners and society [24]. In quality education, not only knowledge, but also skills and attitudes, are prioritized to build up the four pillars of learning. These four major pillars include learning to know, to be, to do, and to live together [26]. Once these objectives are achieved, learners will not only have their learning performance strengthened but have enough capacity to tackle the problems of sustainable development in the future. The contribution of quality education to human and social development will, therefore, be uncountable. For ethnic minority students, the access and maintenance of quality education will significantly facilitate the development of the existing misalignment of educational outcomes. However, one of the major obstacles to achieving quality education is social and economic inequality. In addition, those left behind are the most underrepresented, including ethnic minorities [16].

To achieve the objectives of quality education, a number of studies have agreed upon the four indispensable factors to be involved, namely a well-developed curriculum, in-service teacher training, a safe and effective learning environment, and transformative and cooperative approaches to teaching and learning. For ethnic minorities, [27] highlights the inclusion of indigenous, current, environmental, social and economic issues in mainstreaming quality education. Equality for all without any discrimination is a must and should be the first goal that is realized.

\subsubsection{Multicultural Education}

Multicultural education has been defined by several researchers in different ways [28]. Each definition carries its own distinguished content and explanation, which is why there is no agreed definition in this regard. In the context of the education of ethnic minorities in this research, multicultural education is defined in accordance with [29]. 
Multicultural education is an idea, an educational reform movement, and a process. As an idea, multicultural education seeks to create equal educational opportunities for all students, including those from different racial, ethnic, and social-class groups. Multicultural education tries to create equal educational opportunities for all students by changing the total school environment so that it will reflect the diverse cultures and groups within a society and within the nation's classrooms.

Ref. [30] also puts forward five dimensions of multicultural education. They are content integration, the knowledge construction process, prejudice reduction, an equity pedagogy, and empowering school culture and social structures.

Content integration is the extent to which teachers use examples and content from a variety of cultures and groups to demonstrate their lessons. Prejudice reduction describes lessons and activities used by teachers to help students to develop positive attitudes toward different racial, ethnic, and cultural groups. An equity pedagogy exists when teachers modify their teaching in ways that will facilitate the equal academic achievement of students without discrimination. An empowering school culture and social structure are created when the culture and organization of the school are transformed in ways that enable students from diverse racial, ethnic, and gender groups to experience equality and equal status [29-31].

In this research, multicultural education occurs when, in most primary and secondary classes for ethnic minorities, teachers are mostly Kinh and students are of another ethnic group. On the other hand, in tertiary education, ethnic diversity is greater when students from a variety of ethnic groups share the same class. This context makes it difficult to achieve quality education, as it requires adjustments in general policies and specific pedagogical methods.

\section{Methods}

\subsection{Research Methods}

This study employed the jurisprudence method to explore the relationship between legal theories and practices found in Decision No.622/QD-TTg for the implementation of SDG4 [32]. Once enough documents were synthesized, the perspectives of human rights and the targets of the SDG4 among ethnic minorities were analyzed to gain an insight into the compatibility between them.

An exploratory approach was also utilized, the first step of which involved reviewing the existing literature to compare and contrast the findings, which were used as bases for examining the conditions and barriers in the implementation of SDG4. A survey was also conducted using questionnaires for 160 students together with 140 officials and lecturers at Tan Trao University in Tuyen Quang Province. This questionnaire was newly developed based on the survey tool by [8], previously administered to 960 respondents from eight ethnic groups, namely Cao Lan, Dao, Hoa, Mong, Muong, Nung, San Diu and Tay in Tuyen Quang, Cao Bang and Dien Bien Provinces.

\subsection{Research Instrument}

By reviewing the relevant literature, analyzing related laws and using expert opinions in focus group discussions, four main aspects of equal right to schooling synthesized by [7] were utilized in a search for compatibility with seven targets of SDG4 specific to vulnerable groups. Research by in Tuyen Quang Province on 960 subjects was then investigated in full to obtain data for an analysis of the economic, social, cultural, political and legal conditions for SDG4 realization (Table 3).

Finally, a questionnaire was developed based on the one previously designed by [8]. The questionnaire served to seek the opinions of 300 students, lecturers and officials on the conditions and barriers for guaranteeing equality and human rights in education among ethnic communities on the way to achieving SDG4. Equality and human rights in education involve accessibility, availability, acceptability and adaptability to all educational aspects mentioned in targets of SDG4. The respondents responded to forty statements, which were scored on a five-point Likert scale. A score of one represented 
either the least agreement or the worst condition, whereas a score of five represented either the most agreement or the best condition. Ten additional open questions were included to seek explanations and recommendations. Fifty questions were distributed and targeted to different groups of subjects, as detailed in Table 4 .

Table 3. Variables for research.

\begin{tabular}{cl}
\hline & A1. Accessibility to location and cost \\
Aspects of equal right to & A2. Availability of educational programs and infrastructure \\
schooling (A) & A3. Acceptability of form and content of education \\
& A4. Adaptability of flexible education and vocational training \\
\hline & SDG4.1. Complete free, fair and quality primary and secondary education \\
& SDG4.2. Quality development, early childhood care education for children \\
& SDG4.3. Equal access to quality and affordable vocational and higher \\
education & SDG4.4. Significant increase in skilled workers via vocational training \\
groups (SDG4) & SDG4.5. Equal access to education and training, vocational training for \\
& vulnerable people \\
& SDG4.6. Literacy and numeracy to all young people and adults \\
& SDG4.7. Knowledge and skills necessary to promote the sustainable \\
development \\
C1. Political-legal \\
C2. Economic \\
C3. Socio-cultural \\
C4. Participation motivation \\
B1. Language \\
B2. Child labor \\
B3. Gender inequality \\
B4. Others
\end{tabular}

Table 4. Questionnaire structure.

\begin{tabular}{|c|c|c|}
\hline Content & Number of Questions (\%) & Target Respondents \\
\hline \multicolumn{3}{|c|}{ Conditions - $14(28 \%)$} \\
\hline Political & 4 & Lecturers and Officers \\
\hline Economic & 4 & All \\
\hline Socio-cultural & 4 & Lecturers and Students \\
\hline Participation motivation & 2 & Students \\
\hline \multicolumn{3}{|c|}{ Barriers - 12 (24\%) } \\
\hline Language & 3 & Students \\
\hline Gender inequality & 3 & Students and Lecturers \\
\hline Child labor & 3 & Students \\
\hline Others & 3 & All \\
\hline \multicolumn{3}{|c|}{ Expectations and reality - $8(16 \%)$} \\
\hline Equal rights for schooling & 2 & All \\
\hline SDG targets & 2 & Lecturers and Officers \\
\hline Conditions & 2 & All \\
\hline Barriers & 2 & All \\
\hline \multicolumn{3}{|c|}{ Relation to GI - 4 (8\%) } \\
\hline SDG4.5.1 & 3 & All \\
\hline SDG4.7.1 & 3 & All \\
\hline \multicolumn{3}{|c|}{ Recommendations - 10 (20\%) } \\
\hline
\end{tabular}




\subsection{Sampling Methods}

Tuyen Quang is a province located in the Northern mountainous area of Vietnam. It has 27 ethnic groups, accounting for $52 \%$ of the population of the whole province [8]. Tan Trao University, previously an education college established in 1959, is the only tertiary educational institution in Tuyen Quang, with seven faculties (mostly in liberal arts), eight departments, four centers, one high school, and one clinic. The total annual enrollments are around 13,000. Tuyen Quang is the province whose poverty rate remains high in comparison to other provinces in Vietnam. This entails many difficulties in increasing the number of students pursuing tertiary education as well as improving the education quality of educational institutions within the province. Tan Trao University, despite having the highest-quality staff in Tuyen Quang, still comes across difficulties in consistently maintaining the quality of education for students.

The sample study received responses from a total of 300 respondents of different ethnic backgrounds (Kinh, Dao, Tay, Mong, Muong, Nung) from Tan Trao University. The respondents were divided into three groups based on their roles, namely students, lecturers and officers (Table 5).

Table 5. Sampling.

\begin{tabular}{cccccccc}
\hline Groups & Total (\%) & $\underline{\text { Kinh }}$ & $\underline{\text { Dao }}$ & $\underline{\text { Tay }}$ & $\underline{\text { Mong }}$ & $\underline{\text { Muong }}$ & $\underline{\text { Nung }}$ \\
\hline Students & $160(53.3 \%)$ & $100(33.3 \%)$ & $25(8.33 \%)$ & $15(5 \%)$ & $10(3.3 \%)$ & $5(1.67 \%)$ & $5(1.67 \%)$ \\
Lecturers & $70(23.3 \%)$ & $65(21.7 \%)$ & $2(0.67 \%)$ & $2(0.67 \%)$ & $1(0.33 \%)$ & $1(0.33 \%)$ & $0(0 \%)$ \\
Officers & $70(23.3 \%)$ & $60(20 \%)$ & $2(0.67 \%)$ & $2(0.67 \%)$ & $2(0.67 \%)$ & $2(0.67 \%)$ & $2(0.67 \%)$ \\
Total & $300(100 \%)$ & $225(75 \%)$ & $29(9.67 \%)$ & $19(6.33 \%)$ & $13(4.33 \%)$ & $8(2.67 \%)$ & $7(2.33 \%)$ \\
\hline
\end{tabular}

\subsection{Data Analysis}

Responses from the survey were coded and entered in SPSS Version 20 and checked for reliability using the Cronbach's alpha $(\alpha)$ reliability estimate $(\alpha=\mathrm{N} \rho /[1+\rho(\mathrm{N}-1)])$. A high reliability coefficient was achieved, with Cronbach's $\alpha$ estimates ranging from 0.710 to $0.903(\geq 0.6)$ (Table 6). The corrected item-total correlation estimates ranged between 0.5 and $0.7(>0.3)$, also showing good correlations between the variables.

Table 6. Reliability estimates.

\begin{tabular}{cccc}
\hline Factors & Observed Variables & Cronbach's $\alpha$ & Corrected Item-Total Correlation \\
\hline A & A1, A2, A3, A4 & 0.710 & $>0.3(0.570)$ \\
SDG4 & SDG4.1,SDG4.2,SDG4.3,SDG4.4, & 0.903 & $>0.3(0.642-0.763)$ \\
C & SDG4.5,SDG4.6,SDG4.7 & 0.825 & $>0.3(0.586)$ \\
B & C1, C2, C3, C4 & 0.690 & $>0.3(0.532)$ \\
\hline
\end{tabular}

Following this, an Exploratory Factor Analysis (EFA) was conducted to determine the correlation between sub-targets and to determine their corresponding legal elements. The Kaiser-Meyer-Olkin $(\mathrm{KMO})$ test $(=0.786)$ and Barlett's test $(=0.000)$ (Table 7) showed good correlations between the observed variables.

Table 7. Kaiser-Meyer-Olkin (KMO) and Barlett's Test.

\begin{tabular}{ccc}
\hline Kaiser-Meyer-Olkin measure of sampling adequacy. & 0.786 \\
& Approx. Chi-Square & 3427.532 \\
Bartlett's Test of Sphericity & Df & 168 \\
& Sig. & 0.000 \\
\hline
\end{tabular}

The loading factors $(\geq 0.509)$ as seen from the Rotated Component Matrix (Table 8 ) also showed good correlations between the variables. 
Table 8. Rotated Component Matrix.

\begin{tabular}{ccccc} 
& \multicolumn{4}{c}{ Components } \\
\cline { 2 - 5 } & $\mathbf{1}$ & $\mathbf{2}$ & $\mathbf{3}$ & $\mathbf{4}$ \\
\hline A1 & 0.759 & & & \\
A2 & 0.787 & & & \\
A3 & 0.802 & & & \\
A4 & 0.816 & & & \\
SDG4.1 & & 0.823 & & \\
SDG4.2 & & 0.701 & & \\
SDG4.3 & & 0.792 & & \\
SDG4.4 & & 0.799 & & \\
SDG4.5 & & 0.657 & & \\
SDG4.6 & & 0.728 & & \\
SDG4.7 & & 0.808 & & \\
C1 & & & 0.778 & \\
C2 & & & 0.706 & \\
C3 & & & 0.698 & \\
C4 & & & 0.823 & \\
B1 & & & & 0.715 \\
B2 & & & & 0.638 \\
B3 & & & & 0.822 \\
B4 & & & & \\
\hline
\end{tabular}

\section{Findings}

\subsection{Compatibility between SDG4 and the Human Rights of Ethnic Minorities}

In a review of literature and experts' findings, the study attains that there is a close relationship between quality education and the rights-based approach in achieving sustainable development (Table 9). The [32] points out that equal life-long learning and quality education can only be guaranteed when rights to education, equality and employment are enforced for all, without discrimination.

Table 9. Sustainable development goal 4 (SDG4) related to human rights.

\begin{tabular}{ccl}
\hline SDG4 & \multicolumn{1}{c}{ Related Human Rights } \\
\hline & $\bullet$ & $\begin{array}{l}\text { Right to education including underrepresented groups [33] } \\
\text { Right to equality for minorities [34] and for genders in } \\
\text { 4. Quality education: Ensure inclusive and } \\
\text { equitable quality education and promote } \\
\text { life- long learning opportunities for all. }\end{array}$ \\
\hline
\end{tabular}

A review of seven outcome sub-targets for SDG4 in The United Nations Declaration of Human Rights in 1948 [36] and four elements constituting educational rights in Vietnam illustrates high compatibility. Each sub-target is compatible with a certain aspect of educational rights. Specifically, availability is compatible with SDG4.1 and SDG4.6, accessibility with SDG4.1, SDG4.3, SDG4.5 and SDG4.7, acceptability with SDG4.2 and SDG4.7 and adaptability to SDG4.4 and SDG4.5 (Table 10). 
Table 10. Compatibility between SDG4 and elements of educational rights for ethnic minorities in Vietnam.

\begin{tabular}{cc}
\hline SDG4 & Elements of Education Rights for Ethnic Minorities \\
\hline SDG4.1 & Availability; Accessibility \\
SDG4.2 & Acceptability \\
SDG4.3 & Accessibility \\
SDG4.4 & Adaptability \\
SDG4.5 & Accessibility; Adaptability \\
SDG4.6 & Availability; Acceptability \\
SDG4.7 & Accessibility; Availability \\
\hline
\end{tabular}

4.2. Promotion Conditions and Barriers to Implementing Sustainable Development Goal 4 in Vietnam under the Approach of Human Rights in Ethnic Minority Areas

\subsubsection{Political-Legal Conditions}

The survey used the set of political-legal conditions initiated by [8], which involves legislation (L), policy (P) and strategy system (SS), convention participation (CP) and governmental authority assignment (GAA) (Table 11). When asked to articulate the extent to which they agreed that the State has provided adequate political-legal conditions to improve education for ethnic minorities, 140 lecturers and faculty officers showed a high level of agreement. The mean values for the five elements ranged from 2.46 to 4.49 , confirming that all the conditions were perceived by the respondents to be important or very important to the implementation of SDG4 among ethnic groups. The two most essential elements required, i.e., legislation and governmental authority, are spread out across the seven sub-targets, as shown in Table 11.

Table 11. Political-legal conditions for each sub-target.

\begin{tabular}{cc}
\hline Sub-Target for SDG4 & Political-Legal Conditions \\
\hline SDG4.1 & L, P, CP, GAA \\
SDG4.2 & P, SS, GAA \\
SDG4.3 & CP, L, GAA \\
SDG4.4 & L, SS, CP, GAA \\
SDG4.5 & L, P, SS, CP, GAA \\
SDG4.6 & L, P, GAA \\
SDG4.7 & L, SS, CP, GAA \\
\hline
\end{tabular}

\subsubsection{Economic Conditions for Education}

Three hundred respondents were asked about the extent to which their college and classrooms serve their work and study. The mean value range was $2.3-4.52$, indicating that economic conditions generally underwent satisfactory to good preparation. Responses also reveal noticeable improvements in economic subsidization by the Vietnamese government for ethnic minorities in their access to tertiary education. Specifically, $100 \%$ of ethnic minority students received a monthly stipend, which was adequate to cover their college-life expenses. Moreover, ethnic students were provided with free accommodation in the dormitory system of the college. Their transportation to school was also assisted with a bus system, taking them from their dormitory to the college campus and vice versa. More importantly, all ethnic students enjoyed free-of-charge education in all departments of Tan Trao University. Such economic support was widely recognized among ethnic minorities and was considered to be efficient in relieving the economic burden of many ethnic families, and thus highly encouraging to ethnic minority youngsters, giving them access to quality tertiary education. 


\subsubsection{Socio-Cultural Conditions and Participation Motivation of Ethnic Minorities}

One of the questions to 160 students and 70 teachers was "to what extent are you aware of the education environment that you are in having more than one ethnic?" The responses revealed a mean ranging from 2.1 to 3.5, showing a satisfactory to high level of awareness of multicultural education. When asked about the extent to which such an environment helped them become more aware of who they were in the classroom, the respondents showed a satisfactory level of self-awareness of their identity when the mean ranged between 2.3 and 2.5. The student respondents showed very high agreement in their pride in attending school, with means ranging from 3.07 to 4.59 .

\subsubsection{Barriers to Implementing Sustainable Development Goal 4 in Vietnam}

A total of 300 respondents to the survey questions were asked to rate the extent to which they agreed that ethnic minorities in Vietnam were facing barriers in their access to the educational system. Three major obstacles, including language, gender inequality and child labor, were examined in relation to other obstacles, as seen in the question "to what extent do you agree that children in ethnic families have to work to earn meals or money?" The data collected reveal a high level of agreement among the 300 respondents. The mean values for the four obstacles ranged from 3.78 to 4.09 , confirming that all the obstacles were faced by the respondents. The hindrance found to be the biggest to overcome was child labor, whereas the most improvement was found to be in terms of gender inequality (Table 12).

Table 12. Barriers for SDG4 implementation.

\begin{tabular}{cc}
\hline Barriers & Percentage \\
\hline Language & $60 \%$ \\
Gender inequality & $20 \%$ \\
Child labor & $65 \%$ \\
Others & $37 \%$ \\
\hline
\end{tabular}

4.2.5. Assistance That Each Target, Condition and Barrier Removal Provides to the Access of Ethnic Minorities to Human Rights in Education

The mean differences between targets, conditions and barrier removal variables reveal the differences between their expected assistance and the reality in relation to the implementation of SDG4, while guaranteeing access to and enjoyment of education for all ethnic minorities "without anyone left behind" (Figure 1). The most remarkable differences belong to SDG4.7, C3 and C2.

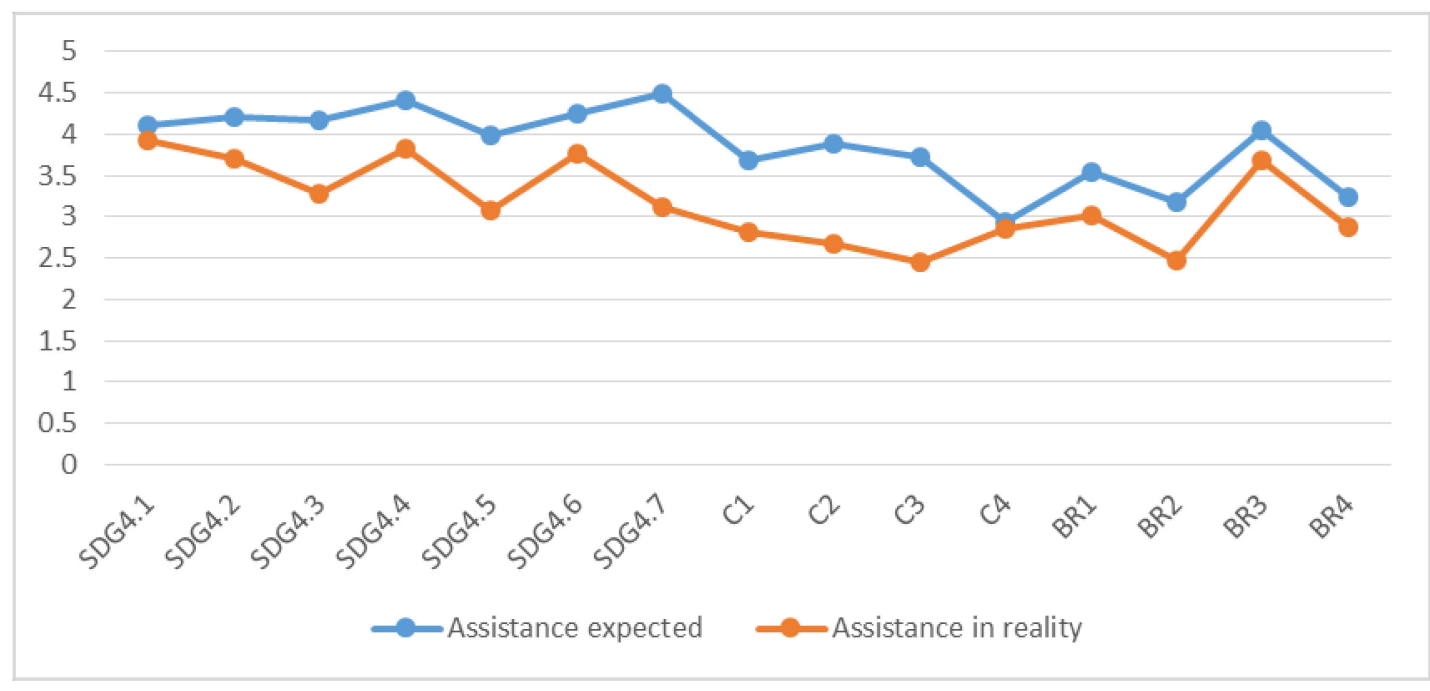

Figure 1. Assistance in theory and in reality in the implementation of SDG4 for ethnic minority groups. 
Regarding the compatibility of SDG targets with the lowest mean differences of all contents, it was disclosed that the highest compatibility was achieved in the high expectation for the aid given to ethnic minorities, as well as providing the best assistance for SDG4 implementation among ethnic minorities when brought into practice. On the other hand, the highest mean difference between the seven targets belonged to SDG4.7. This means SDG4.7 was perceived as the most important factor in carrying out SDG4.

Of all the conditions surveyed for SDG4 implementation, C1 and C4 received the lowest mean difference - that is, the legal-political condition and participation motivation were the two preparations that were in closest relation to their theoretical expectation. Participation motivation among ethnic minorities was high in both theory and reality. Ethnic minority people took great pride in being involved in the national development route. Nevertheless, the mean differences between C 2 and C 3 were the largest out of all fifteen elements. This means that, despite the importance that the economy and socio-cultural factors held in the implementation, the real conditions did not meet the expectations.

Concerning barrier removal, the most marked difference occurred for child labor, followed by language. This means that solutions to removing the barriers of child labor and language differences to make access to quality education available to all ethnic minorities were not as efficient as expected (Figure 1).

\section{Discussion}

The study finds that all the targets of SDG4 in combination can meet the requirements of human rights to education for ethnic minorities. In particular, the implementation of the two most-related ones, Targets 4.5 and 4.7, can guarantee all four As, namely availability, accessibility, acceptability, and adaptability. This finding confirms the righteousness of the Vietnamese government in localizing SDG4 to better manage the education progress, particularly for ethnic minority communities [7,10,37-39]. More importantly, the detailed compatibility helps the government to enact more effective laws and policies that prioritize Targets 4.5 and 4.7 in the context of a multi-ethnic country. The finding also resonates with $[9,40]$ in that the authority's governance plays a fundamental role in enforcing and applying the laws, policies and strategies to achieve SDG4 among ethnic minorities. This outcome also reveals the faith ethnic minority people have in their government in the effort to achieve sustainable development with their powerful legal and managerial tools [41]. Particularly, in an educational regard, the finding agrees with [8] about the importance of mainstreaming national education policies that involve gender equality and human rights. The legal framework in the process of both boosting its effectiveness and ensuring the basic human rights of ethnic minorities during law enforcement, especially for disadvantaged groups $[9,40,42]$. The national strategies that the Vietnamese government has set up are believed to far surpass the standards set by the global SDG4 version and to meet all aspects required for the rights of ethnic minorities in Vietnam, while adapting global goals to local needs [43]. The political system also makes a proper appeal to the authorizing bodies to take charge of the implementation, including mainly the Ministry of Education and Training and Ministry of Labor, Invalids and Social Affairs, in coordination with other related ministries and departments. This has received high agreement from most people surveyed. However, dilemmas in terms of placing ethnic minority issues at the forefront in the national education system were identified as limitations in a constitutional capacity [44].

The economic conditions surveyed reveal both improvements and difficulties in supporting access to quality education for ethnic minority people. The finding first discloses the satisfactory to good preparation of infrastructure for the education of ethnic minorities at a tertiary level. Previous studies (for example $[7,8]$ ) recognize that the main infrastructure, including schools, classrooms and sanitary systems, are in the progress of fulfilling the standard for all levels of education for ethnic minorities. Notably, $100 \%$ of communes in Tuyen Quang have schools for pre-, primary and lower secondary education levels. Semi-boarding, boarding, vocational and preparatory schools are increasing in number. However, economic difficulties remain an obvious hindrance to the access to quality education 
of ethnic minorities. Moreover, despite enjoying a low cost or free-of-charge education, the access to education of ethnic minorities is far lower than that of the Kinh at all levels (Figure 2).

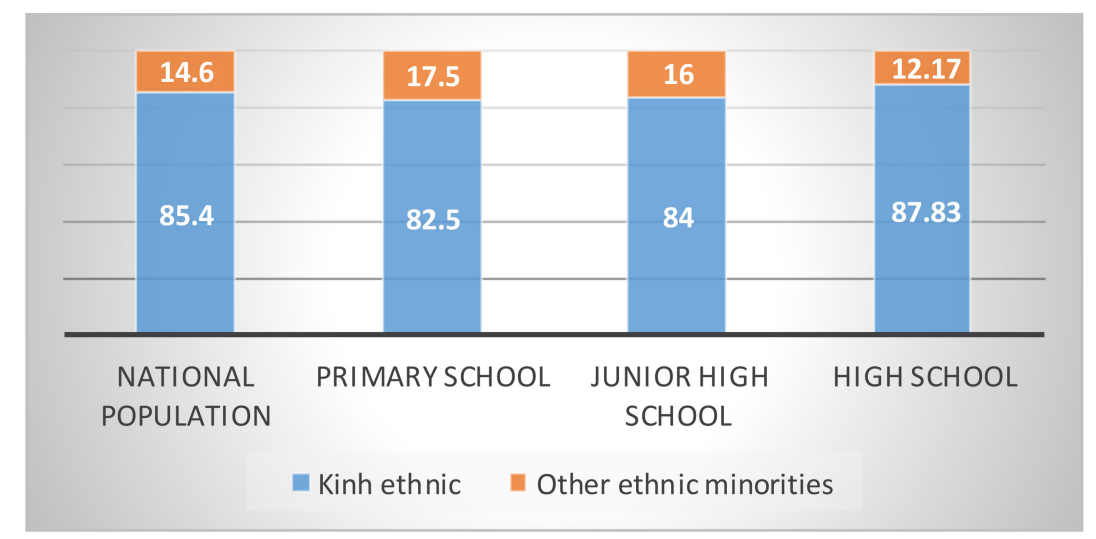

Figure 2. Access to education in Vietnam in 2014 [45].

Previous statistics confirm the financial hardship of ethnic minority communities by claiming that, by accounting for $15 \%$ of the population of the whole country, ethnic minorities take up $47 \%$ of the poor and $68 \%$ of the extremely poor. Some of the reasons for the sluggishness in improving this situation are the harsh geography and natural terrains, which are mostly mountainous. The deprived cultural background of ethnic minority groups, such as due to outdated rituals or opposing customs, is another cause of the slow and hindered economic development in ethnic communities [1,41,46-48].

Socio-cultural conditions that provide multicultural education for ethnic minority people also raise much debate. In the context of multi-ethnic classrooms, it is found that a multi-cultural environment both helps and hinders inclusive education. According to [28], an awareness of the positives and negatives can bring both eagerness and worry in the studied context. On the one hand, teachers are under more pressure to adjust their lessons to suit all ethnic minorities involved in the classroom. This poses challenges to delivering lessons and reduces much motivation of teachers in the face of economic difficulties [49]. Similarly, students may have trouble integrating themselves into the environment [50]. On the other hand, the opportunities for promoting self-identification [51] and equity in the educational system [52] were also found in the respondents' answers. The negatives mentioned affect quality education to a certain extent and thus, the result, in reality, needs more investigation and improvements. As found by [8], social-cultural drawbacks such as a low level of education can entail low-paid employment (65\%) and unskilled workers (36\%) in ethnic minority communities nationwide. However, the negatives cannot stop ethnic minorities from showing their pride in attending classes. This echoes [8]'s conclusion on the aspiration of many ethnic minorities to attend school. Such a finding can, in return, inspire the Vietnamese government to fulfill the educational rights of ethnic minorities for their comprehensive and sustainable development.

The barriers hinder to a great extent the implications of human rights and thus negatively affect the quality of education for ethnic minorities. This outcome resonates with most research in the related field $[8,44,45,53-56]$. For gender inequality, the finding makes it clear why, globally, the gender gap index for education attainment in Vietnam in 2020 is ranked $93^{\text {rd }}$, down five positions compared to $2019[57,58]$. In Asia Pacific, the country ranked $10^{\text {th }}$ in 2019, also seeing a decline compared with other countries in the region [58]. While [44,59] claims that ethnic minority women face a double challenge for representation and participation in formal and informal decision-making structures in families and communities, this investigation finds that such challenges nearly disappear. Ethnic minority women receive more respect and recognition for their abilities and roles. The line between the two genders is also highly agreed to be fading. 
Child labor is considered an infringement of the human rights law and is becoming a thorny issue for the Vietnamese government to tackle [57]. Constraining the practice of child labor has many shortcomings because most families in ethnic groups have to send their children into the labor force to make their ends meet [8]. According to [60], in 30\% of ethnic minority families, at least one child drops out of school to work, which is a high rate. In Vietnam, the number of students going to school at the right age remains low and the quality of education at each level in several ethnic minority communities does not yet meet the national standard [7].

At the same time, language barriers are perceived as being hard to overcome due to the conflict between the often poor command of Vietnamese among ethnic minority people and the wide availability of materials written in Vietnamese rather than in ethnic minority languages [54]. This sometimes discourages ethnic minority people from taking classes or finishing their programs. It is stated that over $90 \%$ of ethnic minority children speak their mother tongues at home. Many of them are barely exposed to the Vietnamese language before the first year of schooling [60]. Accordingly, Vietnamese ethnic minority students have trouble acquiring fluency and comprehension in their class. Simultaneously, teachers of ethnic minority classes encounter similar language conundrums in finding materials and using language in their classes. Such a quandary has led to difficulties in implementing multicultural education and achieving quality education. The protection and preservation of the values of each language are posing many challenges to the government in enforcing ethnic minorities' human rights $[8,61]$. The removal of other problems, such as family violence and limited vocational skills, was also perceived as significant in their assistance in the implementation of SDG4. This echoes what [8] reveals in his research, which confirms the importance of restricting family violence and upgrading vocational skills for ethnic minority people.

\section{Academic and Managerial Implications}

Academics and managers working on the educational issues of ethnic minorities for sustainable development should consider the results of this study to reorient their research direction, as well as to improve their management policies. For academic researchers, since the human rights-based approach for ethnic minorities is not widely studied in the Vietnamese academic community, this study can motivate future investigations into questions of how to improve human rights or which human rights should be prioritized for the education of ethnic minorities. In finding out the conditions for SDG4 implications, further research can discuss the extent of mainstreaming gender equality and human rights into educational policies, curricula, teacher education and student assessment so as to fit the general indicator of Target 4.7. The obstacles that this study examined can ignite some ideas about measuring equality in education using the parity indices, including indigenous versus non-indigenous, male versus female, rural versus urban and bottom versus top wealth groups, so as to fit the general indicator of Target 4.5.

Another noticeable issue that has emerged and which would benefit from further research is multicultural education. In the context of Vietnam, multicultural education for ethnic minorities receives little interest, despite its significance in creating a breakthrough in the education of ethnic minorities and ensuring human rights. In terms of managerial implications, firstly, the research has revealed the high compatibility of SDG targets and elements of human rights, confirming the righteousness in the nationalization of the SDGs in the Vietnamese context. This encourages more actions in making laws, policies and strategies appropriate and detailed for ethnic minority communities so that equality and no discrimination in education for every citizen of the country can be achieved. Furthermore, the Vietnamese government should adjust the legal system of Vietnam with more effective laws, strategies and policies to better suit the needs of ethnic minorities in education. For managers in the education field, this research provides some ideas in adjusting curricula, teaching and learning textbooks in order to lessen the negative attitudes and misconceptions about ethnic minorities. The inclusion of positive contents and inspiring images about ethnic minorities in educational materials should be seriously considered. More significantly, the research raises an awareness of the barriers that impede 
the implications of SDG4 for ethnic minorities. Thus, policymakers should be aware that they must deal with child labor, language, gender inequality and other barriers to education.

\section{Concluding Remarks}

Since education is the leading factor for the development of the whole country, especially of ethnic minority groups, implementing SDG4 among ethnic minorities and enforcing human rights is an unavoidable but intimidating task for both the Vietnamese government and Vitenamese people. From this perspective, this study helps to provide a better insight into the compatibility between the targets of SDG4 and the elements of human rights for ethnic minorities. This study confirms that coordinating the implications of all the targets can satisfactorily ensure the legal rights of ethnic minorities. The Vietnamese government has also shown all-round preparations for the implementation of SDG4 in terms of the economic, legal political and socio-cultural conditions for ethnic minority communities. Moreover, provoking the motivation of ethnic minority groups and encouraging participation is vitally important due to its positive impact on sustaining the spirit of ethnic minorities. Though challenges remain, particularly due to the language barrier, child labor and gender inequality, considerable efforts to improve them have been recognized.

The limitations of this research lie in several aspects. Firstly, the jurisprudence method encountered trouble in terms of access to the legal documents, so the finding concerning compatibility is fairly limited. Secondly, for the exploratory method, the quality of data analysis was influenced by the assignment of different groups to different questions. The overlap of answers made it quite confusing to classify a few questions into the proper section for analysis. Furthermore, a limitation can be found in the number of respondents who were selected from one university in one mountainous province in the north. This constrains the generalization of the findings. Finally, due to the limited scope of the study, only four conditions and three major barriers were analyzed in general. This may restrict the overview of the hardship that the implementation of SDG4 has faced and somehow underestimate the real situation. However, these limitations can provide perspectives for further research. Particularly, further studies with a larger sample of educational institutions from pre-school, primary and upper levels all over Vietnam, or other multi-ethnic countries, might be undertaken to triangulate the research findings. Further studies might also focus on more specific conditions, such as the infrastructure in the economic area. Other barriers could also be explored in more detail.

Author Contributions: Conceptualization, T.T.; methodology, D.-N.-M.D.; supervision, C.-M.L. and T.T.; writing-original draft, L.-K.H.; writing-review \& editing, C.-M.L. All authors have read and agreed to the published version of the manuscript.

Funding: This research was funded by the Vietnam National Foundation for Science and Technology Development (NAFOSTED) under grant number 02/NCUD/2019.

Acknowledgments: We sincerely thank the reviewers for their valuable comments, which helped us improve the quality of the paper.

Conflicts of Interest: The authors declare no conflict of interest.

\section{References}

1. Research Center for Human Rights of Ethnic Minority and Mountainous People (HRC). Population and distribution of ethnic minorities in Vietnam. In Ethnic Eco; Research Center for Human Rights of Ethnic Minority and Mountainous People (HRC): Hanoi, Vietnam, 2015.

2. Voluntary National Review. Vietnam's Voluntary National Review_Key Massages. 2018. Available online: https://sustainabledevelopment.un.org/memberstates/vietnam (accessed on 25 April 2020).

3. Tsalis, T.; Malamateniou, K.; Koulouriotis, D.; Nikolaou, I. New challenges for corporate sustainability reporting: United Nations' 2030 Agenda for sustainable development and the sustainable development goals. Corp. Soc. Responsib. Environ. Manag. 2020. [CrossRef]

4. United Nations. Transforming Our World: The 2030 Agenda for Sustainable Development; United Nations: New York, NY, USA, 2015. 
5. Pereira, J.D. Equity, Access and Educational Quality in Three South-East Asian Countries—The Case of Indonesia, Malaysia and Viet Nam; The HEAD Foundation: Singapore, 2016.

6. Schmitz, H.P. A human rights-based approach (HRBA) in practice: Evaluating NGO development efforts. Polity 2012, 44, 523-541. [CrossRef]

7. Do, M.N.D. Rights of Minorities Ethnic in Vietnam Today; Graduate Academy of Social Sciences: Hanoi, Vietnam, 2017.

8. Do, M.N.D. Some Solutions to Ensure the Rights of Ethnic Minorities to Promote the Great National Unity of Tuyen Quang Province. Ph.D. Thesis, Tan Trao University, Tuyen Quang, Vietnam, 2017.

9. Do, T.T. Implementing the Law on Economic, Social and Cultural Rights for Ethnic Minorities in the Northern Mountainous Provinces of Vietnam Today; Ho Chi Minh National Political Academy: Hanoi, Vietnam, 2015.

10. Le, X.T. Ethnic Minority Rights Are in Accordance with International and Vietnamese Laws; Law Faculty: Hanoi, Vietnam, 2015.

11. Livelihood Sovereignty Alliance-LISO. Why Rights to Livelihoods of Indigenous Ethnic Communities in the Mekong Region Matter; Open Development Mekong: Hanoi, Vietnam, 2014.

12. Hawkins, C.A. Sustainability, human rights, and environmental justice. Crit. Soc. Work 2010, 11, 68-81.

13. Langford, M. Human Rights and MDGs in Practice: A Review of Country Strategies and Reporting; Office of the High Commissioner for Human Rights, United Nations: Geneva, Switzerland, 2010.

14. Sachs, J.D. From millennium development goals to sustainable development goals. Lancet 2012, 379, 2206-2211. [CrossRef]

15. Winkler, I.T.; Williams, C. The sustainable development goals and human rights: A critical early review. Int. J. Hum. Rights 2017, 21, 1023-1028. [CrossRef]

16. Benavot, A. Assuring quality education and learning: Lessons from education for all. Prospects 2016, 46, 5-14. [CrossRef]

17. Velázquez, F.D.C.; Méndez, G.M. Augmented reality and mobile devices: A binominal methodological resource for inclusive education (SDG 4). An example in secondary education. Sustainability 2018, 10, 3446. [CrossRef]

18. Samuel, J. (Ed.) Sustainable Development Goals-A Human Rights Based Approach. In Asian Perspectives on International Human Rights Landscapes; Forum Asia: Geneva, Switzerland, 2018.

19. UNESCO Institute for Statistics. Metadata for the Global and Thematic Indicators for the Follow-Up and Review of SDG 4 and Education 2030; UNESCO: Paris, France, 2018.

20. IAEG-SDGs. Tier Classification for Global SDG Indicators. 2019. Available online: https://unstats.un.org/ sdgs/files/Tier-Classification-of-SDG-Indicators-11-December-2019-web.pdf (accessed on 7 May 2020).

21. Pham, H.M. Vietnam's Education. The Current Position and Future Prospects; The Gioi Publishers: Hanoi, Vietnam, 1998.

22. Trieu, Q.; Jayakody, R. Ethnic minority educational success: Understanding accomplishments in challenging settings. Soc. Indic. Res. 2019, 145, 663-701. [CrossRef]

23. National Politics. Ho Chi Minh: Full Set; National Political Publishing House of Vietnam: Hanoi, Vietnam, 2002; Volume 9.

24. Manu, P.O.; Didham, R.J. Quality education for sustainable education: A priority in achieving sustainability and well-being for all. In Policy Brief; Institute for Global Environment Strategies: Kanagawa, Japan, 2014.

25. Benavot, A. Policies toward quality education and student learning: Constructing a critical perspective. Innov. Eur. J. Soc. Sci. Res. 2012, 25, 67-77. [CrossRef]

26. UNESCO. Education 2030-Incheon Declaration and Framework for Action for the Implementation of Sustainable Development Goal; UNESCO: Paris, France, 2015.

27. UNESCO. Education for Sustainable Development Goals: Learning Objectives; UNESCO: Paris, France, 2017.

28. Ozturgut, O. Understanding multicultural education. Curr. Issues Educ. 2011, 4, 4-12.

29. Banks, J.A. Multicultural education: Characteristics and goals. In Multicultural Education; Banks, J.A., Banks, C.A.M., Eds.; Allyn \& Bacon: New York, NY, USA, 1997.

30. Banks, J.A. Multicultural education: Historical development, dimensions, and practice. In Handbook of Research on Multicultural Education; Banks, J.A., Banks, C.A.M., Eds.; Macmillan: New York, NY, USA, 1995; pp. 3-24.

31. Banks, J. (Ed.) Multicultural Education, Transformative Knowledge and Action; Teachers College Press: New York, NY, USA, 1996. 
32. The Prime Minister. Decision on Issuing a National Action Plan to Implement the 2030 Agenda for Sustainable Development; (622/QĐ-TTg); Government of the Socialist Republic of Vietnam: Hanoi, Vietnam, 2017.

33. The United Nations. Universal Declaration of Human Rights (UDHR). 1948. Available online: https: //www.un.org/en/universal-declaration-human-rights/ (accessed on 20 April 2020).

34. OHCHR. Rights of Minority Groups: International Standards and Implementation Guidelines; OHCHR: Geneva, Switzerland, 2010.

35. The United Nations. General Recommendation no. 25, on Article 4, Paragraph 1, of the Convention on the Elimination of All Forms of Discrimination against Women, on Temporary Special Measures; UN Committee on the Elimination of Discrimination against Women (CEDAW): New York, NY, USA, 2004.

36. Kunz, J.L. The United Nations declaration of human rights. Am. J. Int. Law 1949, 43, 316-323. [CrossRef]

37. Nguyen, T.A.T. Sustainable policy for poverty reduction in ethnic minority in northen mountains-Status and solutions. In Proceedings of the Sustainable Development and Ethnic Minority Poverty Reduction in Mountainous Regions, Hanoi, Vietnam, 12 June 2014.

38. Department of Sustainable Development. Synthesis Report Research: Review 17 General Goals and 169 Specific Objectives in the 2030 Agenda for the Sustainable Development of the United Nations to Assess the Situation and Identify Appropriate and Feasible Objectives Exam with the Conditions of Vietnam, Serving as a Basis for Nationalization of Global Sustainable Development Goals; Ministry of Planning and Investment: Hanoi, Vietnam, 2016.

39. Baker, R.G. Educating ethnic minorities in Vietnam: Policies and perspectives. Kappa Delta Pi Rec. 2007, 43, 168-173. [CrossRef]

40. Tran, T. Study and Propose Policies to Support the Development of Education and Training in Ethnic Minority and Mountainous Areas in the Period of 2021-2025; Vietnam Academy for Ethnic Minorities: Hanoi, Vietnam, 2017.

41. Dang, H.A. Chapter 8: Vietnam-A widening poverty gap for ethnic minorities. In Indigenous Peoples, Poverty and Development; Cambridge University Press: Cambridge, UK, 2010.

42. Luong, T.T.H.; Phan, T.G.; Truong, Q.H. Research on Customary Laws of Ethnic Minorities and Forest Land Policies in Vietnam. Available online: https://data.opendevelopmentmekong.net/library_record/research-oncustomary-of-ethnic-minorities-and-forest-land-policy-in-vietnam-final-draft (accessed on 19 May 2020). (In Vietnamese)

43. Vietnamese Government. Vietnam's Voluntary National Review on the Implementation of the Sustainable Development Goals. Available online: https://sustainabledevelopment.un.org/content/documents/ 19967VNR_of_Viet_Nam.pdf (accessed on 19 May 2020).

44. The Ethnic Minority Working Group (EMWG). Critical issues in achieving sustainable development of ethnic minorities. In Proceedings of the Sustainable Development and Ethnic Minority Poverty Reduction in Mountainous Regions, Thai Nguyen, Vietnam, 11-13 June 2014.

45. Tran, Q.H. Sustainable development of ethnic minority and mountainous area in Quang Ninh province-Results and the current raised issues. In Proceedings of the Sustainable Development and Ethnic Minority Poverty Reduction in Mountainous Regions, Thai Nguyen, Vietnam, 11-13 June 2014.

46. Luong, T.H. Ethnic minority poverty reduction in mountainous regions and economic geography in Vietnam. In Proceedings of the Sustainable Development and Ethnic Minority Poverty Reduction in Mountainous Regions, Thai Nguyen, Vietnam, 11-13 June 2014.

47. UNICEF; Ethnic Committee; IRC. Multi-Dimensional Poverty of Vietnamese Children in Ethnic Minority Areas: Current Situation, Volatility and Challenges; UNICEF: Hanoi, Vietnnam, 2015.

48. Ethnic Minority Committee; UNICEF. Some Issues about Minorities in International Law; UNICEF: Hanoi, Vietnam, 2001; p. 3.

49. Smith, E.B. Approaches to multicultural education in pre-service teacher education: Philosophical frameworks and models for teaching. Multicult. Educ. 2009, 16, 45-50.

50. Berstein, R. Dictatorship of Virtue: Multiculturalism and the Battle for America's Future; Vintage Books: New York, NY, USA, 1994.

51. Hains, A.H.; Lynch, E.W.; Winton, P.J. Moving towards Cross-Cultural Competence in Lifelong Personnel Development: A Review of the Literature; CLAS Technical Report No. 3; University of Illinois at Urbana Champaign, Early Childhood Research Institute on Culturally and Linguistically Appropriate Services: Champaign, IL, USA, 2000.

52. Banks, J.A.; Banks, C.A.M. Multicultural Education: Issues and Perspectives, 4th ed.; John Wiley: Hoboken, NJ, USA, 2001. 
53. Le, T.H.G. Gender-based violence-Issue of sustainable development and ethnic minority poverty reduction. In Proceedings of the Sustainable Development and Ethnic Minority Poverty Reduction in Mountainous Regions, Thai Nguyen, Vietnam, 11-13 June 2014.

54. Nguyen, T.D. Education and Training in Ethnic Minority Area, Achievements and Emerging Issues; Committee for Ethnic Minorities Affairs Web Portal: Hanoi, Vietnam, 2015.

55. Van de Walle, D.; Gunewardena, D. Sources of Ethnic Inequality in Viet Nam; World Bank: Washington, DC, USA, 2000.

56. Vo, K.V. Education of Human Rights, Theoretical and Practical Issues; Social Science: Hanoi, Vietnam, 2010.

57. World Economic Forum. Global Gender Gap Report 2020; World Economic Forum: Geneva, Switzerland, 2020.

58. Saigoneer. Vietnam down 10 Places in Global Gender Gap Index, Ranks 10th in Asia-Pacific. Vietnamews. Available online: https://saigoneer.com/vietnam-news/18056-vietnam-down-10-places-in-global-gendergap-index,-ranks-10th-in-asia-pacific (accessed on 18 December 2019).

59. IWGIA. Voices of Indigenous Women from Asia Pacific. 2012. Available online: https://www.iwgia.org/ images/publications/0581_Voices_of_I_final.pdf (accessed on 8 May 2020).

60. World Bank. Well begun, not yet done: Vietnam's remarkable progress on poverty reduction and the emerging challenges. In Vietnam Poverty Assessment; World Bank: Hanoi, Vietnam, 2012.

61. Dang, N.T. The Impact of political culture on the human rights-based approach to development in the central highlands of Vietnam. J. Sustain. Dev. 2018, 11, 101-111. [CrossRef]

(C) 2020 by the authors. Licensee MDPI, Basel, Switzerland. This article is an open access article distributed under the terms and conditions of the Creative Commons Attribution (CC BY) license (http://creativecommons.org/licenses/by/4.0/). 